\title{
Valor nutritivo de cultivares de cana-de-açúcar sob irrigação
}

\author{
Nutritive value of cultivars of cane sugar under irrigation
}

\author{
VOLTOLINI, Tadeu Vinhas ${ }^{1 *}$; SILVA, José Gledyson da ${ }^{2}$; SILVA, Wellington Erasmo \\ de Lima ${ }^{2}$; NASCIMENTO, Jorge Messias Leal do²; QUEIROZ, Mário Adriano Ávilaª \\ OLIVEIRA, Anderson Ramos de ${ }^{1}$
}

\footnotetext{
${ }^{1}$ Embrapa Semiárido, Petrolina, Pernambuco, Brasil.

${ }^{2}$ Universidade Federal do Vale do São Francisco, Petrolina, Pernambuco, Brasil.

*Endereço para correspondência: tadeu.voltolini@cpatsa.embrapa.br
}

\section{RESUMO}

Objetivou-se avaliar a composição químicobromatológica e a digestibilidade in vitro da matéria seca (DIVMS) de cultivares de cana-deaçúcar, sujeitas a diferentes lâminas de irrigação. Foram avaliadas as cultivares RB 961003; RB 94-3206; RB 72-454; RB 01-2018; VAT 90-212; RB 01-2046 e RB 92-579, que recebiam as lâminas de irrigação em $100 \%$; $80 \%$; $60 \%$ e $40 \%$ da evapotranspiração real da cultura (ETc) em delineamento em blocos completos, casualizados, e arranjo fatorial em três repetições. Cada parcela foi constituída por sete linhas duplas de plantio, em que o sistema de irrigação utilizado foi o gotejamento subsuperficial com emissores autocompensantes. Aos 12 meses após o plantio, as canas foram cortadas para determinação dos teores de matéria seca (MS), matéria mineral $(\mathrm{MM})$, proteína bruta $(\mathrm{PB})$, matéria orgânica (MO), fibra em detergente neutro (FDN), fibra em detergente ácido (FDA), extrato etéreo (EE) e DIVMS. As cultivares RB 94-3206 e RB 01-2018 se destacaram positivamente em relação aos teores de PB, enquanto a RB 96-1003 destacou-se de forma positiva para a DIVMS. Com a lâmina de irrigação de $100 \%$ da ETc foram obtidos maiores teores de MS e menores valores de DIVMS em relação às demais.

Palavras-chave: composição da cana, irrigação de cana, Saccharum officinarum

\section{SUMMARY}

The objective of this present trial was to evaluate the chemical composition and in vitro dry matter digestibility (IVDMD) of sugarcane cultivars receiving different levels of irrigation water. It were evaluated the cultivars RB 961003, RB 94-3206, RB 72454, RB 01-2018, VAT 90-212, RB 01-2046 and RB 92-579 that received irrigation water of $100 \%, 80 \%, 60 \%$ and $40 \%$ based on real evapotranspiration of sugarcane (ETc) in a completely randomized blocks experimental design and factorial arrangement. Each experimental unit was constituted by cultivation in double lines and the irrigation system was subsurface drip irrigation with compensating emitters. Twelve months after planting, the sugarcanes were cut to determine levels of dry matter (DM), ash, organic matter $(\mathrm{OM})$, crude protein $(\mathrm{CP})$, neutral detergent fiber (NDF), acid detergent fiber (ADF), ether extract (EE) and IVDMD. The cultivars RB 943206 and RB 01-2018 were positively highlighted in relation to CP levels, although RB 961003 had highlighted for IVDMD. Using irrigation of $100 \%$ of ETc were obtained higher DM and lower IVDMD values in comparison with others.

Keywords: Saccharum officinarum, sugarcane composition, sugarcane irrigation 


\section{INTRODUÇÃO}

O Brasil é o maior produtor mundial de cana-de-açúcar (Saccharum spp.) e domina cerca de dois terços da produção mundial. A cana-de-açúcar é a terceira maior atividade agrícola do País em termos de área de produção e de valor bruto produzido e perde apenas para a soja e milho. De acordo com a Companhia Nacional de Abastecimento a área de cana-de-açúcar colhida está estimada em 8.167,5 mil hectares para safra 2010/2011.

Nos últimos anos, observou-se uma valorização crescente do cultivo da cana-de-açúcar em todo país, inclusive para o semiárido brasileiro, que visa, especialmente, à produção de biocombustíveis. Ainda nessa região, outro importante uso dessa planta tem sido destacado: a produção de forragem para a alimentação de ruminantes.

A principal vantagem da cana-de-açúcar como alimento volumoso para animais ruminantes é seu elevado potencial para a produção de forragem, que pode superar 40 toneladas de matéria seca por hectare por ano (MS/ha/ano) em regiões com condições ambientais adequadas para seu cultivo. Nas regiões mais secas do semiárido brasileiro, como o Submédio do São Francisco, com regimes de precipitação pluvial médio de aproximadamente $500 \mathrm{~mm}$, a cana-de-açúcar não pereniza, o que torna necessário o uso da irrigação. Por outro lado, com a aplicação de água em associação às favoráveis condições de luminosidade, radiação solar $\mathrm{e}$ temperatura para o crescimento de plantas forrageiras tropicais, a cana poderá se constituir um importante recurso forrageiro para o Submédio do São Francisco.

Entretanto, além das respostas produtivas há também poucos relatos na literatura nacional e internacional acerca da composição químico-bromatológica, além da digestibilidade in vitro da matéria seca de canas-de-açúcar, cultivadas em áreas irrigadas no semiárido brasileiro. $\mathrm{O}$ conhecimento dessa informação é importante para a elaboração de manejos alimentares e nutricionais adequados para os animais alimentados com essa forrageira e, sobretudo, para compor critérios de tomada de decisão para a escolha das variedades e cultivares a serem mantidas na região com o intuito de obter forragens para a alimentação de ruminantes.

Dessa forma, objetivou-se, neste estudo, avaliar a composição químicobromatológica e a digestibilidade in vitro da matéria seca de sete cultivares de canade-açúcar que receberam, ao longo de seu ciclo, quatro lâminas de água de irrigação.

\section{MATERIAL E MÉTODOS}

O presente estudo foi conduzido no Campo Experimental de Bebedouro, pertencente à Embrapa Semiárido, Petrolina - PE. O cultivo da cana-deaçúcar foi iniciado em novembro de 2009, realizado num solo do tipo Latossolo Vermelho-Amarelo distrófico, cujas características químicas são: $\mathrm{MO}$ de $13,14 \mathrm{~g} / \mathrm{kg} ; \mathrm{pH}(\mathrm{H} 2 \mathrm{O})$ 6,4; 0,21d/Sm; $32,28 \mathrm{mg} / \mathrm{dm} 3$ de $\mathrm{P} ; 0,38 \mathrm{cmolc} / \mathrm{dm} 3$ de $\mathrm{K} ; 1,5 \mathrm{cmolc} / \mathrm{dm} 3$ de $\mathrm{Ca} ; 1,2 \mathrm{cmolc} / \mathrm{dm} 3$ de $\mathrm{Mg} ; 0,03 \mathrm{cmolc} / \mathrm{dm} 3$ de $\mathrm{Na}$; $0,05 \mathrm{cmolc} / \mathrm{dm} 3 \mathrm{de} \mathrm{Al} ; 2,31 \mathrm{cmolc} / \mathrm{dm} 3 \mathrm{de}$ $\mathrm{H}+\mathrm{Al} ; 3,11 \mathrm{cmolc} / \mathrm{dm} 3$ de $\mathrm{S}$ (bases); $5,42 \mathrm{cmolc} / \mathrm{dm} 3$ de CTC e $57 \%$ de saturação de bases, conforme análise. As condições climáticas foram monitoradas durante todo $\mathrm{o}$ experimento $\mathrm{e}$ são apresentadas na Figura 1. 


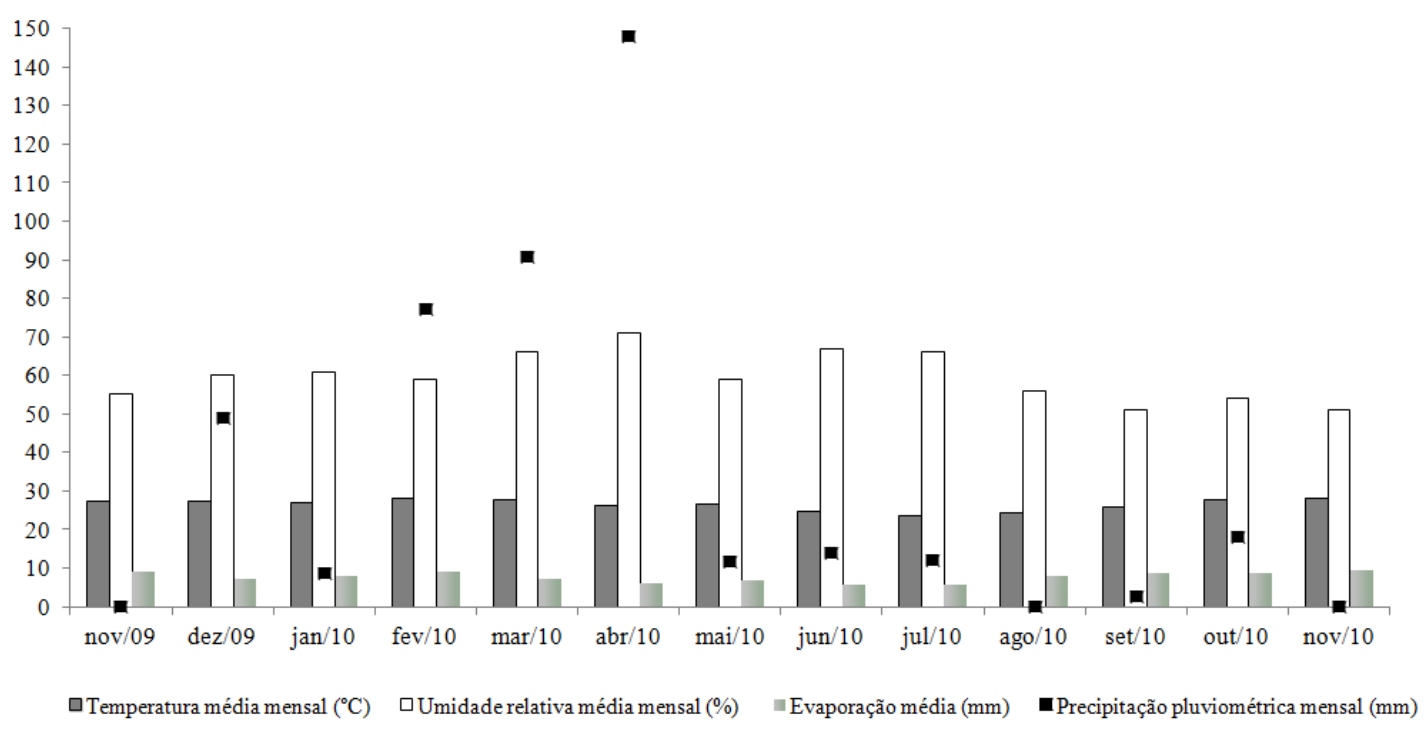

Figura 1. Dados climáticos monitorados durante o período de condução do experimento. Estação Agrometeorológica de Bebedouro (Petrolina$\left.\mathrm{PE} 09^{\circ} 09^{\prime} \mathrm{S} 40^{\circ} 22^{\prime} \mathrm{W}\right)$.

Adotou-se o delineamento experimental em blocos completos casualizados (três blocos) e arranjo fatorial $(7 \times 4)$. Os tratamentos das sete cultivares de canade-açúcar foram assim representados: RB 96-1003; RB 94-3206; RB 72-454; RB 01-2018; VAT 90-212; RB 01-2046 e RB 92-579 e quatro lâminas de irrigação, com três repetições, de modo a totalizar 84 unidades experimentais. As canas-de-açúcar foram adquiridas na Usina Agrovale, em Juazeiro - BA e transferidas para a área experimental. Foram seccionadas em toletes, que continham três gemas cada, e plantadas numa profundidade de aproximadamente 0,20m. Utilizou-se para o plantio, aproximadamente, 15 gemas $/ \mathrm{m}$ linear. $\mathrm{O}$ preparo de solo foi realizado por aração, seguida de gradagem e, próximo à época de plantio, foi realizada nova gradagem, com vistas ao acabamento do preparo do terreno e à eliminação de ervas daninhas. Cada parcela foi constituída por sete linhas duplas de plantio para cada cultivar, com $15 \mathrm{~m}$ de comprimento. As linhas duplas foram espaçadas em 0,40m, enquanto as linhas do sistema de gotejamento subsuperficial foram espaçadas entre si, em 1,6m, de forma a corresponder a uma área de $192 \mathrm{~m}^{2} /$ parcela.

O sistema de irrigação adotado foi o gotejamento subsuperficial, com emissores autocompensantes, espaçados de $0,3 \mathrm{~m}$ entre si. As cultivares receberam a mesma lâmina de irrigação, baseada na Evapotranspiração Real da Cultura (ETc), durante os primeiros 150 dias após o plantio. Após as fenofases 1 (germinação e emergência) e 2 (perfilhamento e estabelecimento da cultura), as cultivares foram submetidas a quatro manejos de lâminas de irrigação distintos: $100 \%$; $80 \%$; $50 \%$ e $30 \%$ da ETc, que foi obtida pela equação:

$\mathrm{ETc}=\mathrm{Kc} \times \mathrm{ETo}$ em que:

ETc = evapotranspiração da cultura da cana-de-açúcar ( $\mathrm{mm} /$ dia);

$\mathrm{Kc}=$ coeficiente da cultura da cana-deaçúcar (adimensional);

ETo = evapotranspiração da cultura de referência (mm/dia) - evapotranspiração de uma cultura de referência (ETo) é uma cultura hipotética, com uma altura 
uniforme de $12 \mathrm{~cm}$, resistência do dossel da cultura de $70 \mathrm{~s} / \mathrm{m}$ e albedo de 0,23 , em pleno crescimento e sem deficiência de água. Tal valor foi obtido na Estação Agrometeorológica de Bebedouro (Petrolina-PE 0909'S 40²2'W).

Foram utilizados valores de $\mathrm{Kc}$, de acordo com os trabalhos de Doorenbos \& Kassam $(1979,1994)$. Com base nos dados meteorológicos disponíveis, foi realizado o cálculo da ETo, baseado nos valores obtidos no tanque de evaporação Classe A.

A adubação de plantio foi baseada em análise de solo para produtividade superior a 100ton./ha de matéria natural (RIBEIRO et al., 1999). A distribuição do nitrogênio e potássio foi feita via fertirrigação, conforme a curva de absorção de nutrientes obtida por Bachchhav (2005). O corte das plantas foi realizado aos 12 meses após o plantio, em novembro de 2010.

A colheita das amostras foi efetuada com a retirada de duas plantas na área útil de cada parcela (unidade experimental). As plantas obtidas foram trituradas em picadeira estacionária e enviadas para o Laboratório de Nutrição Animal da Embrapa Semiárido para a realização das análises químico-bromatológica e para a determinação dos teores de matéria seca (MS), matéria mineral (MM), proteína bruta (PB), matéria orgânica (MO), fibra em detergente neutro (FDN), fibra em detergente ácido (FDA), extrato etéreo (EE) e digestibilidade in vitro da matéria seca (DIVMS), segundo as metodologias descritas por Silva \& Queiroz (2002).

Os parâmetros avaliados foram submetidos à análise de variância e teste de Tukey, pelo procedimento GLM. Quando significativos, foram submetidos à análise de regressão linear e quadrática, por meio do procedimento REG do Statistical Analysis System (SAS INSTITUTE, 2003). Foram considerados como significativos valores de probabilidade inferiores a $5 \%(\mathrm{P}<0,05)$.

\section{RESULTADOS E DISCUSSÃO}

As cultivares e as lâminas de água de irrigação afetaram $(\mathrm{P}<0,05)$ a composição químico-bromatológica e a DIVMS das canas-de-açúcar. Entretanto, não houve interação $(P>0,05)$ entre as cultivares e as lâminas de irrigação para as variáveis avaliadas (Tabela 1). As cultivares influenciaram $(\mathrm{P}<0,05)$ os teores de $\mathrm{PB}$ e a DIVMS, enquanto as lâminas de irrigação afetaram $(\mathrm{P}<0,05)$ os teores de MS e a DIVMS.

A cultivar RB 94-3206 apresentou maior teor de $\mathrm{PB}(\mathrm{P}<0,05)$ em relação a RB 96-1003 e RB 01-2046, sem diferenças entre as demais $(\mathrm{P}>0,05)$. Quanto à DIVMS, a cultivar RB 96-1003 teve maior valor $(\mathrm{P}<0,05)$ em relação à RB 94-3206 e VAT 90-212 (Tabela 1). Em geral, os teores de PB, obtidos no presente estudo, são levemente inferiores aos relatados por Mello et al. (2006), que a partir da avaliação de nove variedades de cana-de-açúcar irrigadas, relataram médias de 2,38\% da MS, ao passo que, no presente estudo, o valor médio foi de $1,73 \%$ da MS. De forma semelhante, França et al. (2005), que também avaliaram nove variedades de cana irrigadas, relataram teores de $\mathrm{PB}$ que variaram de $1,89 \%$ a $3,34 \%$ da $\mathrm{MS}$, valores também próximos aos obtidos no presente estudo.

Em geral, os teores de PB na planta forrageira são baixos, o que foi confirmado pelo presente estudo em área cultivada no semiárido brasileiro. Essa planta é utilizada como ingrediente volumoso nas rações para animais ruminantes, de forma a proporcionar também considerável aporte de carboidratos não fibrosos, o que 
enriquece o aporte energético nas dietas dos animais.

Quanto à DIVMS, os valores encontrados no presente estudo são superiores aos reportados por Carvalho et al. (2010), quando avaliaram nove genótipos de cana-de-açúcar irrigados na região Sul do estado do Bahia. Os valores médios de DIVMS obtidos por Carvalho et al. (2010) variaram de $45,4 \%$ a $68,0 \%$ da MS. Até mesmo os menores valores de DIVMS reportados, no presente estudo, superam os obtidos por Carvalho et al. (2010). Em geral, os valores de DIVMS obtidos são considerados altos e foram possíveis, em razão da escolha das cultivares que são utilizadas pela indústria sucroalcooleira regional para a produção de álcool e que, portanto, possuem altos teores de açúcar, o que favorece a digestibilidade. O manejo aplicado com cortes efetuados aos 12 meses também contribuiu para a obtenção de forragem com as características apresentadas.

Tabela 1. Composição químico-bromatológica (matéria seca - MS, matéria mineral MM, matéria orgânica - MO, fibra em detergente neutro - FDN, fibra em detergente ácido - FDA, proteína bruta - PB, extrato etéreo - EE e digestibilidade in vitro da matéria seca (DIVMS) de sete cultivares de canade-açúcar

\begin{tabular}{lccccccc}
\hline & \multicolumn{7}{c}{ Cultivares de cana-de-açúcar } \\
\cline { 2 - 8 } Item $^{1}$ & RB & RB & RB & RB & VAT & RB & RB \\
& $96-1003$ & $94-3206$ & $72-454$ & $01-2018$ & $90-212$ & $01-2046$ & $92-579$ \\
\hline MS & $29,8^{\mathrm{A}}$ & $30,5^{\mathrm{A}}$ & $30,5^{\mathrm{A}}$ & $31,4^{\mathrm{A}}$ & $29,5^{\mathrm{A}}$ & $29,3^{\mathrm{A}}$ & $28,5^{\mathrm{A}}$ \\
MM & $1,4^{\mathrm{A}}$ & $2,2^{\mathrm{A}}$ & $1,4^{\mathrm{A}}$ & $3,9^{\mathrm{A}}$ & $1,6^{\mathrm{A}}$ & $1,7^{\mathrm{A}}$ & $1,7^{\mathrm{A}}$ \\
MO & $98,6^{\mathrm{A}}$ & $97,8^{\mathrm{A}}$ & $98,7^{\mathrm{A}}$ & $96,1^{\mathrm{A}}$ & $98,4^{\mathrm{A}}$ & $98,3^{\mathrm{A}}$ & $98,3^{\mathrm{A}}$ \\
FDN & $36,2^{\mathrm{A}}$ & $41,0^{\mathrm{A}}$ & $33,8^{\mathrm{A}}$ & $39,9^{\mathrm{A}}$ & $40,8^{\mathrm{A}}$ & $37,1^{\mathrm{A}}$ & $37,7^{\mathrm{A}}$ \\
FDA & $24,4^{\mathrm{A}}$ & $30,8^{\mathrm{A}}$ & $25,4^{\mathrm{A}}$ & $32,9^{\mathrm{A}}$ & $26,8^{\mathrm{A}}$ & $25,0^{\mathrm{A}}$ & $27,4^{\mathrm{A}}$ \\
PB & $1,4^{\mathrm{B}}$ & $2,1^{\mathrm{A}}$ & $1,6^{\mathrm{AB}}$ & $1,8^{\mathrm{AB}}$ & $1,7^{\mathrm{AB}}$ & $1,5^{\mathrm{B}}$ & $1,7^{\mathrm{AB}}$ \\
EE & $0,4^{\mathrm{A}}$ & $1,1^{\mathrm{A}}$ & $0,8^{\mathrm{A}}$ & $0,6^{\mathrm{A}}$ & $0,7^{\mathrm{A}}$ & $0,9^{\mathrm{A}}$ & $1,2^{\mathrm{A}}$ \\
DIVMS & $83,0^{\mathrm{A}}$ & $72,8^{\mathrm{B}}$ & $79,9^{\mathrm{AB}}$ & $74,5^{\mathrm{B}}$ & $73,9^{\mathrm{B}}$ & $76,9^{\mathrm{AB}}$ & $76,4^{\mathrm{AB}}$ \\
\hline
\end{tabular}

${ }^{1}$ Com base na matéria seca $(\%)$.

Médias na linha seguidas pela mesma letra não diferem $(\mathrm{P}>0,05)$ pelo teste Tukey.

Os teores de MS, MM, MO, FDN, FDA e EE das cultivares avaliadas estão de acordo com os valores relatados na literatura nacional para cana-de-açúcar irrigada. Mello et al. (2006) reportam em teores de MS, MM e EE de canas irrigadas, valores que variaram de $22,45 \%$ a $26,90 \% ; 2,26 \%$ a $3,47 \%$ e $0,61 \%$ a $0,89 \%$, respectivamente, que são bastante próximos aos obtidos no presente trabalho. Já, quanto
FDN e FDA os valores obtidos por Mello et al. (2006) que variaram de $44,18 \%$ a $52,06 \%$; $28,38 \%$ a $33,47 \%$, respectivamente, são maiores e, portanto, piores aos observados no presente estudo. Tais números contribuem na confirmação de que as cultivares avaliadas associadas ao manejo de cultivo aplicado foram importantes para a obtenção de material forrageiro de boa qualidade para a alimentação de animais ruminantes. 
Azevêdo et al. (2003a), Azevedo et al. (2003b) e Rabelo et al. (2010) em suas avaliações da composição químicobromatológica de diversos genótipos de cana-de-açúcar, também relatam valores de FDN superiores aos observados no presente estudo. Isso sugere que, na presente pesquisa, a fração que representa os carboidratos teve alta participação de açúcares, já que o teor de fibras foi menor, em comparação com outros estudos, o que é positivo, visto os carboidratos não fibrosos $(\mathrm{CNF})$ proporcionarem maior energia às rações em relação aos carboidratos fibrosos (CF). Elevados teores de FDN podem prejudicar a ingestão de cana-deaçúcar e, em consequência, o consumo de energia. Além disso, elevados teores de FDN pode reduzir a digestibilidade da MS.

O uso de lâminas de irrigação em 100\% da ETc proporcionou maiores teores de MS, em relação ao uso de $80 \%(\mathrm{P}<0,05)$, sem diferenças entre as demais lâminas testadas $(\mathrm{P}>0,05)$, conforme a Tabela 2, o que pode estar relacionado com a planta numa idade fisiológica mais avançada em razão do maior aporte hídrico. Tal comportamento é relatado por Correia e Nogueira (2004), Figuerôa et al. (2004) e Pimentel e Perez (2000) com cana-deaçúcar ou outras plantas forrageiras e justificado pelo maior crescimento vegetativo e perfilhamento das plantas, além de maior alongamento das células vegetais, que aumentam em consequência dos teores de MS das plantas.

Tabela 2. Composição químico-bromatológica e digestibilidade in vitro da matéria seca (DIVMS) de cultivares de cana-de-açúcar que receberam diferentes lâminas de irrigação com base na evapotranspiração real da cultura (ETc)

\begin{tabular}{|c|c|c|c|c|c|c|}
\hline \multirow{2}{*}{ Item $^{1}$} & \multicolumn{4}{|c|}{ Lâminas de Irrigação (\% ETc) } & \multirow{2}{*}{ EPM } & \multirow{2}{*}{$\operatorname{Pr}>\mathrm{F}$} \\
\hline & 40 & 60 & 80 & 100 & & \\
\hline MS & $29,2^{\mathrm{AB}}$ & $30,5^{\mathrm{AB}}$ & $28,8^{\mathrm{B}}$ & $30,7^{\mathrm{A}}$ & 0,62 & 0,01 \\
\hline MM & $1,5^{\mathrm{A}}$ & $1,9^{\mathrm{A}}$ & $1,9^{\mathrm{A}}$ & $2,5^{\mathrm{A}}$ & 0,19 & NS \\
\hline MO & $98,5^{\mathrm{A}}$ & $98,2^{\mathrm{A}}$ & $98,1^{\mathrm{A}}$ & $97,5^{\mathrm{A}}$ & 0,19 & NS \\
\hline FDN & $38,6^{\mathrm{A}}$ & $35,2^{\mathrm{A}}$ & $39,4^{\mathrm{A}}$ & $39,1^{\mathrm{A}}$ & 1,50 & NS \\
\hline FDA & $28,5^{\mathrm{A}}$ & $25,1^{\mathrm{A}}$ & $26,0^{\mathrm{A}}$ & $29,9^{\mathrm{A}}$ & 1,48 & NS \\
\hline PB & $1,9^{\mathrm{A}}$ & $1,5^{\mathrm{A}}$ & $1,6^{\mathrm{A}}$ & $1,7^{\mathrm{A}}$ & 0,13 & NS \\
\hline $\mathrm{EE}$ & $0,6^{\mathrm{A}}$ & $0,8^{\mathrm{A}}$ & $0,9^{\mathrm{A}}$ & $1,0^{\mathrm{A}}$ & 0,11 & NS \\
\hline DIVMS & $79,7^{\mathrm{A}}$ & $80,1^{\mathrm{A}}$ & $77,3^{\mathrm{A}}$ & $71,4^{\mathrm{B}}$ & 1,39 & $<0,0001$ \\
\hline
\end{tabular}

${ }^{\mathrm{T}}$ Com base na matéria seca (\%). NS = Não significativo $(\mathrm{P}>0,05)$; EPM = erro padrão da média.

Médias na linha seguidas pela mesma letra não diferem $(\mathrm{P}>0,05)$ pelo teste Tukey.

Barreto et al. (2001) e Santiago et al. (2001) relatam ainda que há maior acúmulo de MS na cana-de-açúcar a partir da desidratação da forragem, devido à concentração dos solutos do conteúdo celular, o que explicaria os valores intermediários de MS para as lâminas com $60 \%$ e $40 \%$ em relação a ETc.
A aplicação de lâmina de irrigação em $100 \%$ da ETc promoveu menor $(\mathrm{P}<0,05)$ DIVMS da forragem em comparação com as demais lâminas aplicadas, que por sua vez não afetaram a DIVMS da canade-açúcar $(\mathrm{P}>0,05)$, conforme a Tabela 2, também justificado pelo avanço da idade fisiológica da planta. A menor DIVMS com a aplicação de $100 \%$ da ETc sugere 
que com a aplicação dessa quantidade de água, o corte da forragem pode ser realizado em intervalo de tempo menor a fim de que sejam obtidos valores de digestibilidade maiores. Entretanto, valor de DIVMS da ordem de $71,37 \%$ para cana-de-açúcar é considerado elevado.

A partir da análise de regressão para a DIVMS, dentro das lâminas de irrigação, constatou-se comportamento linear significativo, em que para todos os genótipos de cana-de-açúcar avaliados, obteve-se a equação $\hat{Y}=84,18-2,89 x$, em que $\hat{Y}$ refere-se à DIVMS e $x$ às lâminas de água aplicadas. Além disso, o coeficiente de determinação $\left(\mathrm{R}^{2}=0,2395\right)$ foi baixo, fato atribuído a dispersão dos valores de DIVMS ente as cultivares.

A deficiência hídrica, normalmente, causa atraso na maturidade da planta, bem como redução no crescimento e retardamento no desenvolvimento do colmo, o que produz plantas com maior relação folha:colmo e, consequentemente, com maiores taxas de digestibilidade, o que pode ter ocorrido no presente estudo. As cultivares de cana-de-açúcar RB 961003; RB 94-3206; RB 72-454; RB 012018; VAT 90-212; RB 01-2046 e RB 92-579 cultivadas em áreas irrigadas no Submédio do São Francisco apresentam composição bromatológica e digestibilidade in vitro da matéria seca compatíveis com plantas cultivadas em outras regiões brasileiras e que as condicionam a serem utilizadas como ingredientes nas rações de ruminantes dessa região brasileira. Este estudo constatou que se pode optar pela RB 961003 para a obtenção de maiores digestibilidades ou pela RB 94-3206 para maiores teores de proteína bruta.

As lâminas de irrigação, em relação à evapotranspiração real da cultura, possibilitaram a obtenção de material forrageiro de adequada qualidade nutricional, o que facilitam variações no manejo da cultura, em relação a aplicação de água com variações de $40 \%$ a $80 \%$ da ETc, sem prejuízos a composição químico-bromatológica e a DIVMS da cana-de-açúcar. Lâminas de irrigação de $100 \%$ da ETc aceleram o crescimento da planta, reduzindo a DIVMS, o que possivelmente poderá ser contornado com a antecipação na idade de corte da planta.

\section{REFERÊNCIAS}

AZEVÊDO, J.A.G.; PEREIRA, J.C.; CARNEIRO, P.C.S.; QUEIROZ, A.C.; BARBOSA, M.H.P.; FERNANDES, A.M.; RENNÓ, F.P. Avaliação da divergência nutricional de variedades de cana-de-aúcar (Saccharum spp.).

Revista Brasileira de Zootecnia, v.32, n.6, p.1432-1442, 2003a.

AZEVÊDO, J.A.G.; PEREIRA, J.C.; QUEIROZ, A.C.; CARNEIRO, P.C.S.; LANA, R.de P.; BARBOSA, M.H.P.; FERNANDES, A.M.; RENNÓ, F.P. Composição químico-bromatológica, fracionamento de carboidratos e cinética da degradação in vitro da fibra de três variedades de cana-de-açúcar (Saccharum spp.). Revista Brasileira de Zootecnia, v.32, n.6, p.1443-1453, 2003b.

BACHCHHAV, S.M. Fertigation technology forincreasing sugarcane production. Indian Journal of

Fertilisers, v.1, n.4, p.85-89, 2005.

BARRETO, G.; LIRA, M.A.; SANTOS, M.V.; DUBEUX, J.C.B. Avaliação de clones de capim-elefante (Pennisetum Purpureum Schum.) e de um híbrido com o milheto (Pennisetum glaucum (L.) R. Br.) submetidos a estresse hídrico. Revista Brasileira de Zootecnia, v.30, p7-11, 2001. 
CARVALHO, M.V.; RODRIGUES, P.H.M.; LIMA, M.L.P.; ANJOS, I.A.; LANDELL, M.G. A.; SANTOS, M.V.; SILVA, L.F.P. Composição bromatológica e digestibilidade de canade-açúcar colhida em duas épocas do ano. Brazilian Journal of Veterinary

Research and Animal Science, v.47, n.4, p.298-306, 2010.

CORREIA, K.G.; NOGUEIRA, R.J.M.C. Avaliação do crescimento do amendoim (Arachis hypogaea L.) submetido a déficit hídrico. Revista de Biologia e Ciência da Terra, v.4, n.2, p.2, 2004.

DOOREMBOS, J.; KASSAN, A.H. Yield response to water. Rome: FAO, 1979. 212p. ( Irrigation and drainage paper, 33).

DOORENBOS, J.; KASSAM, A.H. Efeito da água no rendimento das culturas. Campina Grande: Universidade Federal da Paraíba, 1994. 306p.

FIGUEIRÔA, J.M.; BARBOSA, D.C.A.; SIMABUKURO, E.A. Crescimento de plantas jovens de Miracrodruon urundeuva Allemão (Anacardiaceae) sob diferentes regimes hídricos. Acta Botânica Brasílica, v.18, n.3, p.573-580, 2004.

FRANÇA, A.F.S.; MELLO, S.Q.S.; REYES BORJAS, A. los.; B.R.A.; MUNDIM, S.P.; MAGALHÀES, M.R.F.; MATOS, T.R.A.; REIS, J.G. Avaliação do potencial produtivo e das características químico-bromatológicas de nove variedades de cana-de-açúcar irrigada. Livestock Research for Rural Development, v.17, n.1, 2005.

Retrieved September 21, 111, from http://www.lrrd.org/lrrd17/1/souz17007. htm.
MELLO, S.Q.S.; FRANÇA, A.F.S.; LIMA, M.L.M.; RIBEIRO, D.S.; MIYAGI, E.S.; REIS, J.G. Parâmetros do valor nutritivo de nove variedades de cana-de-açúcar cultivadas sob irrigação. Ciência Animal Brasileira, v.7, n.4, p.373-380, 2006.

PIMENTEL, C.; CRUZ PEREZ. A.J. de La. Estabelecimento de parâmetros para avaliação de tolerância à seca, em genótipos de feijoeiro. Pesquisa Agropecuária Brasileira, v.35, n.1, p.31-39, 2000.

RABELO, C.H.S.; REZENDE, A.V.de.; RABELO, F.H.S.; NOGUEIRA, D.A.; VIEIRA, P.de F. Composição químicobromatológica da cana-de-açúcar hidrolisada com cal virgem. Revista Brasileira de Saúde e Produção Animal [Online], v.23, n.4, p.135-143, 2010.

RIBEIRO, A.C.; GUIMARÃES, P.T.G.; ALVAREZ, V.H. (Ed.). Recomendações para o uso de corretivos e fertilizantes 1999 em Minas Gerais - $5^{\text {a }}$

Aproximação. Viçosa: Comissão de Fertilidade do Solo do Estado de Minas Gerais, 1999. 359p.

SANTIAGO, A.M.P.; NOGUEIRA, R.J.M.C.; LOPES, E.C. Crescimento de plantas jovens de Mimosa caesalpiniifolia Benth cultivada sob estresse hídrico.

Revista Ecossistema, v.26, n.1, p.23-30, 2001.

SAS INSTITUTE. SAS/STAT: guide for personal computer. Version 9.1. Cary, 2003. 235p.

SILVA, D.J.; QUEIROZ, A.C. Análise de alimentos: métodos químicos e biológicos. 3.ed. Viçosa: Universidade Federal de Viçosa, 2002. 235p.

Data de recebimento: 06/10/2011

Data de aprovação: 26/05/2012 